This item was submitted to Loughborough's Research Repository by the author.

Items in Figshare are protected by copyright, with all rights reserved, unless otherwise indicated.

\title{
A critical discussion of the Community Readiness Model using a case study of childhood obesity prevention in England
}

PLEASE CITE THE PUBLISHED VERSION

http://dx.doi.org/10.1111/hsc.12139

PUBLISHER

(C) Wiley-Blackwell

VERSION

AM (Accepted Manuscript)

\section{PUBLISHER STATEMENT}

This work is made available according to the conditions of the Creative Commons Attribution-NonCommercialNoDerivatives 4.0 International (CC BY-NC-ND 4.0) licence. Full details of this licence are available at: https://creativecommons.org/licenses/by-nc-nd/4.0/

\section{LICENCE}

CC BY-NC-ND 4.0

\section{REPOSITORY RECORD}

Kesten, Joanna M., Paula L. Griffiths, and Noel Cameron. 2019. "A Critical Discussion of the Community Readiness Model Using a Case Study of Childhood Obesity Prevention in England”. figshare. https://hdl.handle.net/2134/17870. 


\title{
A critical discussion of the 'Community Readiness Model' using a case study of childhood obesity prevention in England
}

\author{
Joanna May Kesten, Paula Griffiths, Noel Cameron
}

\begin{abstract}
Recent reforms to the public health system in England aim to generate co-ordinated action between local authorities, healthcare systems and communities to target local health priorities. To support this effort researchers must contribute and evaluate appropriate strategies for designing interventions tailored to community specific needs. One strategy is to apply the Community Readiness Model (CRM), which uses key informant interviews to assess a community's readiness to address local issues. This article presents a critical discussion of the CRM developed from a case study of obesity prevention in pre-adolescent girls within a community in the United Kingdom. Data were collected between February and November 2011. We offer lessons learnt and recommendations relating to: 1) modifications to the interview guide; 2) key informant identification; 3) conducting interviews to theoretical saturation; 4) using key informants to define their community; 5) key informants ability to respond on behalf of the community; 6) using a qualitative model with a quantitative scoring system; and 7) the optimum application of the transcript scoring. In conclusion, the CRM can help researchers, health professionals and local authorities identify the priorities of a community. It is recommended that users of the model be careful to: identify and recruit suitable key informants with the help of the community under study; select an appropriate 'community' and utilise the qualitative findings to strengthen the interpretation of the readiness score.
\end{abstract}

Key Words: Childhood Obesity, Community Readiness Model, Critical Appraisal

Highlights

What is known about this topic

- Childhood obesity prevention is a public health concern.

- Communities will vary in terms of the risk behaviours and the resources available to address the issue; therefore efforts that are successful in one community may not be successful elsewhere.

- Community readiness to accept the intended change is an important influencing factor for successful interventions.

What this paper adds

- Shows that the Community Readiness Model (CRM) is a useful tool for assessing readiness to address childhood obesity prevention.

- Recommends that researchers using the CRM consider the suitability of the key informants; select an appropriate 'community' and utilise the qualitative findings to strengthen the interpretation of the readiness score. 


\section{Introduction}

Childhood obesity is a public health concern. Reforms to the public health system in England aim to generate co-ordinated action between local authorities, healthcare systems and communities to identify and target local health priorities. The Government in England, emphasises the requirement for tailored approaches "which work best for local people", to address obesity, because communities will vary in their needs (Department of Health, 2011: 6). Community-based approaches which encompass the context of the family, school and health-care environment in which childhood obesity develops are supported within the international literature (Kesten, Griffiths, \& Cameron, 2011). Therefore, researchers, local government and healthcare practitioners require tools to help design tailored community-level obesity prevention interventions.

The Community Readiness Model (CRM) offers such an approach and proposes the integration of a "community's culture, resources and level of readiness" (Plested, et al. 2006) to effectively address community issues. 'Readiness' refers to the preparedness of a group to "take action on an issue" (Plested et al. 2006: 3). The model was developed from Psychological Readiness (Trans-theoretical Model of Stages of Change (Prochaska \& Velicer, 1997)) and Community Development (Innovative Decision Making Model and Social Action Process) traditions (Oetting et al. 1995, Thurman, 2000). Details of the model's development and application can be found elsewhere (Oetting et al. 1995). Briefly, the first step of the model is to identify the issue under study and the 'community' with reference to the issue (Figure 1).

--Insert Figure 1 here-- 
The CRM defines a community as a "geographical area, a group within that area, an organization, or any other type of identifiable 'community'” (Plested et al. 2006: 6). The community's stage of readiness to address the issue is determined by identifying and conducting key informant interviews. Key informants are defined as having a good understanding of the issue under study, representing different areas of the community and as being capable of planning and helping to implement the interventions (Plested et al. 2006, Thurman, 2000). The CRM proposes identifying and interviewing approximately six key informants. This number of people is believed to allow an accurate scoring of readiness (Plested et al. 2006). The model is applied using an adaptable semi-structured interview guide consisting of approximately 30 questions (Plested et al. 2006). The interview transcripts are then analysed to generate a score for each of the six dimensions of the interview guide (Table 1) and an overall community readiness stage.

--Insert Table 1 here--

There are 9 'anchored rating statements' for each dimension. Each 'anchored rating statement' is compared to the transcript through repeated readings of the text. The transcripts are analysed in their entirety for each 'anchored rating statement' because there may be instances where information relating to one dimension occurred in a different section of the transcript. The researcher analyses each interview transcript for evidence supporting the first 'anchored rating statement'. If this is found the researcher moves to the next 'anchored rating statement'. Once an 'anchored rating statement' is reached which is not reflected in the transcripts, the previous statement's number is recorded. Once all of the dimensions for every transcript have an anchored rating score, a mean is taken, firstly, for each dimension across all the interviews (Plested et al. 2006) and then across all the dimensions to 
produce an overall community readiness score. The resulting community readiness score falls between 1 ('No awareness') and 9 ('Professionalisation') (Figure 2). The readiness stage is used to develop and implement strategies that are appropriate for the community. The strategies for stages 1-4 involve raising community awareness in terms of: the issue (1-'No awareness'); the presence of the problem within the community (2-'Denial'); the ability of the community to solve the issue (3-'Vague awareness') and the ability to develop concrete ideas to reduce the problem (4-'Preplanning'). Finally, the effectiveness of the implemented strategies is evaluated by recalculating the community readiness score.

--- Insert Figure 2 here ---

The CRM was originally developed to address alcohol and drug abuse prevention (Oetting et al. 1995) but has been applied to multiple community health problems internationally. The model has been applied to childhood obesity prevention in America (Findholt, 2007, Sliwa et al. 2011, Ehlers et al. 2013) and Australia (Millar et al. 2013).

The CRM allows tailor-made and readiness-appropriate strategies to be developed by identifying (Plested et al. 2006) testable theories of what might work. CRMdeveloped interventions are expected to achieve more effective behaviour change (Oetting et al. 1995, Donnermeyer, 1997) and to be more sustainable (Plested et al. 2006) than interventions which do not take into account the community's readiness to change. Although, to the authors' knowledge, the latter theory has not been empirically tested, there is some evidence supporting the proposition that readiness can be increased. For example, Millar (2013) used the CRM for pre-post intervention readiness assessments (Millar et al. 2013) and showed that the "It's your move!" 
intervention significantly increased the readiness stage of intervention schools whilst the readiness of control schools did not significantly change. Furthermore, intervention schools achieving the greatest reductions in overweight and obesity prevalence also increased their community readiness the most (Millar et al. 2013).

This paper presents a critical discussion of the CRM developed from a case study of obesity prevention in pre-adolescent girls (7-11 years) within a community in the United Kingdom (UK). The original aspects of this paper are, firstly, the presentation of lessons learnt in practice, as opposed to theoretical critiques of the model (Beebe et al. 2001, Mayer, 2008). Secondly, this research is the first to apply the CRM in the UK, therefore its critique is valuable for those interested in the model's applicability to the UK as well as internationally.

Previous critiques of the CRM (Beebe et al. 2001; Mayer, 2008) have questioned the development and process of applying the model. The CRM was developed from qualitative reviews and therefore was not developed or evaluated using established psychometric principles (Beebe et al. 2001). However, others have argued that the model is a qualitative construct which doesn't claim to be a quantitative or psychometric tool and that the numerical classification of qualitative data facilitates comparison between communities (Sliwa et al. 2011). No assessment of external validity of this instrument to measure a community's readiness has been attempted (Beebe et al. 2001). In response to this critique, the CRM authors' have previously stated that construct validity cannot be assessed using this model because it is a "broad scale theory", although it is possible to test hypotheses produced from these theories which would then suggest construct validity (Plested et al. 2006). Achieving consistency between-researchers so that the same interview can be coded as the same stage of readiness by two independent researchers is a proxy measure of 
validity (Plested et al. 2006). Additionally, Sliwa and colleagues suggest it would be difficult to validate a construct such as 'readiness' with objective tools (Sliwa et al. 2011). Indeed, what is perhaps more important is the community's perceptions of what is happening, rather than an objective understanding of what is actually happening. For example there may be community initiatives available to address the issue but the community may possess low awareness of them.

Regarding the model's application, Beebe and colleagues were sceptical about whether individuals are capable of identifying the knowledge and awareness of an issue in the community (Beebe et al. 2001). Similarly, the selection of key informants may affect the outcome of the model; indeed those who are most interested in an issue may have a higher stage of readiness than the actual community. Therefore the readiness assessment may reflect the views of a "vocal minority" (Beebe et al. 2001). A further criticism is the small number of suggested interviews used to represent the views of a community (Beebe et al. 2001). Even with small numbers of key informant interviews, it has been suggested that the identification, recruitment and interviewing of key informants is time- and resource-intensive (Beebe et al. 2001) and that the anchored rating scale technique for scoring the transcripts provides the researcher with too much discretion (Beebe et al. 2001). Beebe and Mayer (Beebe et al. 2001, Mayer, 2008) disagree with the assumption that all communities will fit succinctly into one of the nine categories of readiness.

\section{Methods}

The aim of the case study was to assess a community's readiness to adopt behaviours (healthy eating and drinking [HED] and physical activity [PA]) associated with the prevention of obesity in pre-adolescent girls. These findings were used to 
inform recommendations for an intervention. For more details of this case study please refer to (Kesten et al. 2013). The HED readiness score achieved the 'Preparation Stage', at which the CRM suggests the community has active leaders who are planning efforts to which the community offers modest support. The PA readiness score reached the 'Initiation Stage' whereby information is available to justify the efforts in place. The most appropriate initial targets for intervention in this community are the lowest scoring dimensions: 'community knowledge of the issue' and 'resources'. To address the 'community's knowledge of the issue', increasing the awareness of the prevalence of pre-adolescent girls' health behaviours at the local community level is a priority. Additionally, inconsistent school food policies appeared to contribute to tensions between schools and parents and should therefore be addressed within an intervention. An intervention priority for the resources dimension is to support the development of HED efforts beyond the school and invest more in physical education training for primary school teachers.

This research was performed within the East Midlands Region of the UK in the Charnwood Borough of Leicestershire. The Charnwood Borough was viewed as an appropriate community because it hasn't previously engaged in a similar community-based programme; it is geographically contained; and is an appropriate size for this type of research (approximately 166,100 inhabitants) (Office for National Statistics, 2012). It is demographically comparable to the English population. On average $84.3 \%$ of the Borough's inhabitants are 'White British' (Office for National Statistic, 2012), the percentage of children living in poverty is 13.8\% (Regional and local division office for national statistics, 2014) and the prevalence of overweight and obesity in 10-11 year old children is similar to the 
rest of England (32\% and 33.9\% respectively) (National Obesity Observatory, 2013).

The paradigm to which this research adhered most closely was the "interpretative" approach (O'Donoghue, 2007). To identify the key informants of pre-adolescent girls' health behaviours from their own perspective, 13 focus groups were conducted with 56 pre-adolescent girls, in 8 schools within the community (Kesten, 2013).

From these focus groups, the following key informants were identified: 'celebrities', doctors, dentists, dinner staff, grandparents, Government, girl-guide leaders, headteachers, neighbours, parents, friends, sports coaches, siblings, school cooks, shopkeepers, and teachers (Table 2). The following key informants were considered ineligible for interview: celebrities; dentists; doctors; grandparents; neighbours; siblings; and the peer group. Reasons for their ineligibility have been cited elsewhere (Kesten, et al. 2013). Briefly, the key informant were limited to those who could be considered community members rather than health professionals or celebrities, those capable of answering the questions (e.g. not siblings or friends) and who could feasibly be recruited.

To assess the level of community readiness, 33 key informants were purposively recruited to achieve a sample reflecting varying levels of area and individual level deprivation through written letters and snowball sampling approaches. School key informant deprivation level was classified using the Index of Multiple Deprivation for the school area (Communities and Local Government, 2012) and parents were classified using the National Statistics-Socio-economic Classification produced through self-reported assessment of occupation (Office of National Statistics, 2012). 
Participants were interviewed once by JMK within the researcher's institution, at the participant's workplace or home between February and November 2011 (Kesten et al. 2013). Prior to the interview the participant's written informed consent was sought and their permission was obtained for the interview to be audio recorded. The ethical advisory committee at Loughborough University approved this research project (including the focus groups with pre-adolescent girls) (R10-P10) on the 24/03/2010.

\section{Critical appraisal of the CRM}

We offer lessons learnt and recommendations relating to: 1) interview guide modification; 2) key informants identification; 3) conducting interviews to theoretical saturation; 4) using key informants to define their community; 5) key informants' ability to respond on behalf of the community; 6 ) using a qualitative model with a quantitative scoring system; and 7) the optimum application of the transcript scoring.

\section{Modifications to interview guide}

The CRM developers encourage adaptation of the model to suit the research purpose (Plested et al. 2006). Previous CRM users haven't discussed how they adapted the model to their specific circumstances which means it isn't clear precisely how those studies were conducted. Therefore, for clarity and to give some idea of the scope of possible adaptations, this section outlines the adaptations made to the model in the current case study.

Terminology

As the model was developed in the USA, the terminology of the interview guide was modified to ensure the questions were accessible to an audience from the UK. The term "leaders" was changed to 'important, influential or key people' because this 
could mean anybody who was seen as important not just those who are employed to perform certain behaviours.

Defining the target group

The interview guide doesn't state to whom you are referring with regards to the issue. The primary interest in this research was pre-adolescent girls; therefore this was stipulated in every question and in the introduction for clarity.

Behaviour specific responses

The interview questions were repeated once for HED and once for PA because these behaviours were considered distinct. This ensured that it was possible to ascertain to which behaviour the responses related and, whilst analysing the transcripts, 'readiness' for HED and PA could be assessed separately to identify potential differences in 'readiness' on which to target an intervention.

Defining a community

Every question in the CRM interview guide refers to the key informant's 'community'. The concept of 'community' can be defined in many ways, which some argue has meant the term has lost its meaning (McLeroy et al. 1988). To address this issue, at the beginning of the interview the researcher asked the respondent "How would you describe the community you operate in?" This approach resulted in the key informants identifying several communities including school, religious, parental and geographic communities. One participant repeated that she is part of a community of parents who encourage children to be active and to eat healthily and felt that low PA and unhealthy dietary habits were not of concern in her community. 
"Researcher: Do you think there's any barriers with parents not wanting to do that or not being able to provide a healthy lunch?

Participant: But you're talking about in my community. I have heard of people who complained about that. I heard that somebody was complaining because their child had an unhealthy lunch box but I don't know that person, she's not in my community."

(Parent 1, Most Deprived School)

The above extract illustrates that key informant responses are informed by the definition of a community that has been adopted. This has implications for an intervention in a community where there appear to be sub-communities of parents. Key informants working across the entire community commented on the multiple communities that exist in relation to deprivation levels:

"You go out to the villages and they're quite affluent areas, then you come into town and there are some schools where children are quite deprived..." (School Food Advisor)

Encouraging the key informants to define their own community provided clarity about the community context within which their opinions sit, however the variability and diversity of these definitions makes interpretation of the overall community situation complex. Despite this complexity, understanding how the term 'community' is conceptualised is important for designing interventions.

Specific key informant questions

It can be argued that in addition to their understanding of community readiness, the personal views of the key informants are important. Hence, this research added interview questions specific to each key informant type based on issues which had arisen in the focus groups with pre-adolescent girls and couldn't be addressed using the CRM. For instance, parents were asked about the influence of siblings, the children's friends and pets on their child's health actions.

\section{Key informant identification}


It has previously been noted that those selected as key informants by researchers may not be viewed as such by the community itself (Sliwa et al. 2011). The majority of previous studies using the CRM have failed to identify key informants from the target population's perspective which may mean that not all relevant key informants are interviewed. One of the earliest studies using the CRM employed focus groups to determine who the community itself viewed as key informants (Plested et al. 1999). This case study used focus groups with the target population (pre-adolescent girls). Examples of key informants who may not have been identified in this study without this approach, due to the limited attention they have received in the academic literature, are shop-keepers and school dinner staff. These key informants also tended to reach lower 'anchored rating statements' (indicating lower community readiness) suggesting that shop-keepers and dinner staff may be good initial targets for interventions.

Number of interviews

Qualitative researchers often aim to reach a point of 'theoretical saturation' whereby no new concepts are elicited by conducting more interviews (Glaser \& Strauss, 1967). The CRM fails to acknowledge the value of this approach and instead proposes a small number of interviews (Beebe et al. 2001). This research sought to achieve 'theoretical saturation' and, as a result, recruited more than the model's suggested number of key informants. By working to saturation it is anticipated that a fuller, more conceptually representative, picture of the community has been created and that obtaining the views of 33 key informants allowed the key themes to be corroborated across a broad range of key informants.

Responding on behalf of the community 
One critique of the interview guide is the suggestion that key informants can respond on behalf of their community (Beebe et al. 2001). In a minority of instances, in the current case study, the key informants didn't want to attempt to offer such a response, "I can't answer on behalf of the rest of the community." (Parent). Additionally, some parents commented on their own child and parenting practices rather than the community:

"If she [daughter] had a choice between an apple, you know a bowl of fruit and sweets, you know for her the sweets taste better. I mean it is [a constant battle]."

(Parent 1, Most Deprived School 1)

Only a minority of participants experienced difficulty in responding on behalf of the community. This finding suggests that researchers should only score the parts of the transcripts where the key informant is talking about the community rather than individuals, so as to avoid presenting individual's perceptions as community experiences.

\section{Scoring system}

We propose that researchers using the model should not neglect the qualitative findings because they are rich, informative and useful as intervention design tools. In contrast there are limitations associated with the scoring procedures of the model, as recognised by others (Beebe et al. 2001, Mayer, 2008), which mean that findings have to be interpreted within these constraints.

In the case study an in-depth qualitative analysis of the transcripts was performed prior to using the CRM scoring system (described earlier) to produce an overall readiness stage. The thematic qualitative analysis (Braun \& Clarke, 2006) consisted of line-by-line coding of the transcripts into initial features of the data. The content of 
these codes was then read and compared across other codes to iteratively refine and group codes into potential themes.

Conducting a qualitative analysis of the transcripts is advisable because: it provides the reader with detailed evidence supporting the CRM scoring; highlights the complexity of the community and of the issue being addressed; identifies the specific needs of the community as viewed by key informants; and captures the variation in community readiness both within and between key informants.

In this case study the lowest readiness score was produced by the shop-keepers. From the quantitative scores it was ascertained that shopkeepers would be a relevant target group for intervention, but little information is gained about how to intervene. The qualitative analysis revealed that these key informants appear to be more concerned with their profits than with the healthfulness of the products they sell:

"If you have lots of it [fresh produce], it will probably go out of date. It's only got a limited life on it hasn't it? Well you start losing money then"

(Shop-keeper 1)

From examining the qualitative data, a useful intervention strategy could be to provide shop-keepers with incentives and promotional tools to help maximise the profits achieved from selling healthier products.

By removing the qualitative, contextual information it becomes difficult to develop behaviour change initiatives suitable for the community which is one of the model's theoretical underpinnings. Although the CRM agree is fundamentally a qualitative tool (Sliwa et al. 2011), only a limited number of the articles published using the model, report qualitative support for their CRM score (Findholt, 2007, Lawsin et al. 
2007, McCoy et al. 2007; Plested et al. 1999; Plested et al. 2007) and of those that do, none provide any detailed, systematic, qualitative analysis. Instead some appear to select a small number of quotes or provide limited anecdotal evidence to illustrate a score. One explanation for this could be that a thorough qualitative analysis is more time-consuming than the CRM's quantitative scoring system and there are normally time constraints associated with designing and implementing an intervention.

Whilst the CRM score obtained can be used to draw comparisons between communities (Sliwa et al. 2011), the factors contributing to this score will be specific to each individual community, therefore to design an appropriate intervention it is important to understand these differences. The recommendation from the case study is to emphasise the qualitative nature of the data and to encourage those who might use the model in the future to place quantitative assessment derived from the model within the context of these rich qualitative findings, thus providing evidence of the quality and rigour of the qualitative analysis conducted.

\section{Transcript scoring}

Although the interview guide encourages a discussion of the strengths and limitations of community initiatives, the interview scoring guide does not allow any examination of the effectiveness of initiatives. Instead the 'anchored rating statements' relate to the community's awareness of initiative effectiveness and evaluation efforts (Plested et al. 2006). Therefore, although there may be initiatives which have been in place for several years, the perceived quality and effectiveness of these initiatives cannot be incorporated into the readiness scoring. For example, in 
this case study, although there are opportunities available in the community for children to participate in PA, some children may be unable to access them:

"[There's a] number of children who actually don't get the chance to participate just because they haven't got the transport or parents are working." (Deputy Head-teacher 1, Least Deprived School)

"They'll [children] bring a leaflet home for holiday activities and it's in xx or Xxx [two large city's approximately 20-40 minutes' drive away] and obviously we don't drive and also it's probably 25, 30 pound for the week which when you're on benefits is an awful lot of money."

(Parent 2, Most Deprived School)

It can be argued that initiative effectiveness is not necessarily a construct of readiness. Instead the CRM measures whether community members are likely to change their behaviours by assessing their current knowledge of the issue, what they are already doing and their support of the available efforts. However, understanding the perceived effectiveness of current or previous programmes can help to design new initiatives. Therefore it is argued that a qualitative analysis of the effectiveness of the efforts already in place is also required.

The CRM developers state that "to receive a score at a certain stage, all previous levels must have been met up to and including the statement which the scorer believes best reflects what is stated in the interview" (Plested et al. 2006: 15). The problem with this approach is that statements referring to a higher 'anchored rating statement' supersede those referring to lower stages resulting in the issues relating to these lower-level comments not being reflected in the final readiness stage. The CRM developers state that readiness "assignment should not be made simply on the basis of average ratings on the dimension; it should be a qualitative expert judgement based on all of the interview information and the scores on the anchored rating scales", (Oetting et al.1995) however it isn't clear from the scoring procedure 
how these decisions should be negotiated. In this case study a deputy head-teacher commented that:

"The majority of them [parents] support it [PA initiatives] whole-heartedly and are keen to come and watch should there be anything taking place."

(Deputy Head-teacher 1, Least Deprived School)

This comment was coded in the 'Community Climate' section as reaching the $7^{\text {th }}$ 'anchored rating statement': "The majority of the community generally supports programs, activities, or policies. "We have taken responsibility"'” (Plested et al. 2006). However, when discussing circumstances in which members of the community might think that low PA behaviours in pre-adolescent girls should be tolerated, (another concept included in the Community Climate dimension) the same teacher commented:

"I'd say there should not be [situations in which low PA is tolerated] but I think there clearly are (...) again the majority of children are I would say grossly unfit."

(Deputy Head-teacher 1, Least Deprived School)

This comment was coded as meeting the second 'anchored rating statement': 'The prevailing attitude is "There's nothing we can do," or "Only 'those' people do that," or "We don't think it should change". This example illustrates that by taking the highest score achieved the lower of these two comments is not considered in the readiness score. We recommend that researchers consider the pervasiveness of the perspectives, if several strongly emphasised comments suggest the community should be scored at a low score for a dimension while a less-pervasive comment is made at a higher stage, the researcher should consider scoring at the lower stage or at least consider the implications of the weighting of the comments that have been scored for intervention design. 
In addition, qualitative interpretations should highlight any contradictions within the data. This is in line with recommendations made by Mayer (2008). In contrast, Beebe and colleagues (2001) propose using a survey design to assess readiness which, arguably, diminishes the richness of information which can be obtained.

Contradictions within qualitative data are demonstrated by research using the model to inform the design of an obesity prevention intervention (Findholt, 2007). In this community teachers were reportedly highly-respected and school staff were viewed as concerned about child health behaviours. By contrast, child health was viewed as a family concern with which schools shouldn't be involved. In reflecting on this finding, Findholt highlights the importance of qualitatively analysing the data alongside the readiness score to allow these contradictions and potential barriers to effective intervention to be elicited (Findholt, 2007).

\section{Conclusions}

There is a demand for community-tailored approaches to tackle public health issues such as childhood obesity (National Institute for Health and Clinical Excellence, 2012). Assessing readiness to adopt behaviour changes that may prevent obesity is one approach for designing community-tailored interventions and can help researchers and local authorities identify the needs of a community and appropriate actions which are acceptable to the community. The authors recommend that users of the CRM be careful to: identify suitable key informants; select an appropriate 'community'; and utilise the qualitative findings to strengthen the interpretation of the readiness score.

\section{Source of Funding}


This research was completed as part of JMK's PhD studentship supported by the Health \& Life Sciences Research School at Loughborough University.

\section{Competing interests}

The author(s) declare that they have no competing interests.

\section{Authors' contributions}

JMK carried out the interviews, transcribed and analysed the transcripts and led the drafting of the paper. NC conceived the research, supervised the data collection and contributed to the drafting of the paper. PG supervised the data collection, contributed to the analysis of the data and contributed to the drafting of the paper.

\section{Acknowledgements}

We thank the schools and key informants from the Charnwood Borough community who agreed to participate in this research. 


\section{References}

Beebe, T. J., Harrison, P. A., Sharma, A., \& Hedger, S. (2001). The community readiness survey. development and initial validation. Evaluation Review, 25(1), $55-71$.

Braun, V., Clarke, V. (2006). Using thematic analysis in psychology. Qualitative Research in Psychology, 3(2),77-101.

Communities and Local Government: Indices of Deprivation. Available at: [www.communities.gov.uk/communities/neighbourhoodrenewal/deprivation/, 2012.

Department of Health. (2011). Healthy lives, healthy people: A call to action on obesity in england. (Policy No. 16166). HM Government.

Donnermeyer JF. (1997). Community Readiness and Prevention Programs. Journal of the Community Development Society; 28(1), 65-83.

Ehlers, D. K., Huberty, J. L., \& Beseler, C. L. (2013). Is school community readiness related to physical activity before and after the ready for recess intervention? Health Education Research, 28(2), 192-204. doi:10.1093/her/cys102

Findholt, N. (2007). Application of the community readiness model for childhood obesity prevention. Public Health Nursing (Boston, Mass.), 24(6), 565-570. doi:10.1111/j.1525-1446.2007.00669.x

Glaser, B., Strauss, A. The discovery of grounded theory: strategies for qualitative research. Aldine Transaction: New Jersey; 1967. 
Kesten, J., Cameron, N., Griffiths, P.L. (2013). Assessing community readiness for overweight and obesity prevention in pre-adolescent girls: a case study. BMC Public Health, 13, 1205. doi: 10.1186/1471-2458-13-1205.

Kesten, J. (2013)The role of community readiness in the prevention of overweight and obesity in pre-adolescent girls. Loughborough University, Institutional Repository;: http://www.Iboro.ac.uk/services/library/online/repository/

Kesten, J., Griffiths, P. L., \& Cameron, N. (2011). A systematic review to determine the effectiveness of interventions designed to prevent overweight and obesity in pre-adolescent girls. Obesity Reviews, 12(12), 997-1021.

Lawsin, C. R., Borrayo, E. A., Edwards, R., \& Belloso, C. (2007). Community readiness to promote latinas' participation in breast cancer prevention clinical trials. Health \& Social Care in the Community, 15(4), 369-378. doi:10.1111/j.1365-2524.2007.00695.x

Mayer, K. (2008). In response to the published article "application of the community readiness model for childhood obesity prevention (findholt, 2007)". Public Health Nursing, 25(5), 389-389. doi:10.1111/j.1525-1446.2008.00722.x ER

McCoy, H. V., Malow, R., Edwards, R. W., Thurland, A., \& Rosenberg, R. (2007). A strategy for improving community effectiveness of HIVIAIDS intervention design: The community readiness model in the caribbean. Substance use \& Misuse, 42(10), 1579-1592. doi:10.1080/10826080701212535 
McLeroy, K. R., Bibeau, D., Steckler, A., \& Glanz, K. (1988). An ecological perspective on health promotion programs. Health Education Quarterly, 15(4), 351-377.

Millar L., Robertson N., Allender S., Nichols M., Bennett C., Swinburn B (2013). Increasing community capacity and decreasing prevalence of overweight and obesity in a community based intervention among Australian adolescents. Preventive Medicine, 56(6), 379-384.

National Institute for Health and Clinical Excellence. Obesity: working with local communities. 2012;PH42.

National Obesity Observatory: Childhood Obesity and its determinants. BMI classification population monitoring. $\left(85^{\text {th }} / 95^{\text {th }}\right)$ centiles. Children aged $10-11$ years \% overweight and obese. 2011/2012. http://www.sepho.org.uk/noo/NCMP/single/atlas.html

O'Donoghue T. Planning your qualitative research project an introduction to interpretivist research in education. Routledge; 2007.

Oetting, E. R., Donnermeyer, J. F., Plested, B. A., Edwards, R. W., Kelly, K., \& Beauvais, F. (1995). Assessing community readiness for prevention. The International Journal of the Addictions, 30(6), 659-683.

Office for National Statistics. 2011 Census: Ethnic group, local authorities in England and Wales. 2012. Available at: http://www.ons.gov.uk/ons/search/index.html?pageSize=50\&sortBy=none \&sortD irection=none\&newquery=ethnic+group+charnwood+census 
Office for National Statistics. 2011 Census: Usual resident population, local authorities in England and Wales. Available at :

http://www.ons.gov.uk/ons/search/index.html?newquery=population+charnwood+b orough

Office of National Statistics. The National Statistics Socio Economic Classification (NS-SEC rebased on the SOC2010). Available at:

http://www.ons.gov.uk/ons/guide-method/classifications/current-standardclassifications/soc2010/soc2010-volume-3-ns-sec--rebased-on-soc2010--usermanual/index.html\#14, 2012.

Plested, B., Edwards, R., \& Jumper-Thurman, P. (2006). Community readiness: A handbook for successful change. Fort Collins CO, Tri-ethnic Center for Prevention Research.

Plested, B., Smitham, D. M., Jumper-Thurman, P., Oetting, E. R., \& Edwards, R. W. (1999). Readiness for drug use prevention in rural minority communities. Substance use \& Misuse, 34(4-5), 521-544.

Plested, B. A., Edwards, R. W., \& Thurman, P. J. (2007). Disparities in community readiness for HIVIAIDS prevention. Substance use \& Misuse, 42(4), 729-739. doi:10.1080/10826080701202551

Prochaska, J. O., \& Velicer, W. F. (1997). The transtheoretical model of health behaviour change. American Journal of Health Promotion : AJHP, 12(1), 38-48.

Regional and local division office for national statistics. Painting pictures of place series. Local Profiles. Available at: 
http://neighbourhood.statistics.gov.uk/HTMLDocs/Local\%20Profiles\%20V5.0/Localpr ofiles.html. Accessed March 20th, 2014.

Sliwa, S., Goldberg, J. P., Clark, V., Collins, J., Edwards, R., Hyatt, R. R., Economos, C. D. (2011). Using the community readiness model to select communities for a community-wide obesity prevention intervention. Preventing Chronic Disease, 8(6), A150-159.

Thurman, P. J. (2000). Community readiness: A promising model for community healing. U.S Department of Justice Office of Justice Programs Office for Victims of Crime, 1-19.

Thurman, P. J., Plested, B. A., Edwards, R. W., Foley, R., \& Burnside, M. (2003). Community readiness: The journey to community healing. Journal of Psychoactive Drugs, 35(1), 27-31. 
Figures

Figure 1 Process for using the Community Readiness Model Source: Adapted from Plested et al. 2006

Figure 2 The nine stages of Community Readiness

Table

Table 1 Six dimensions of readiness that influence a community's preparedness to take action on an issue 


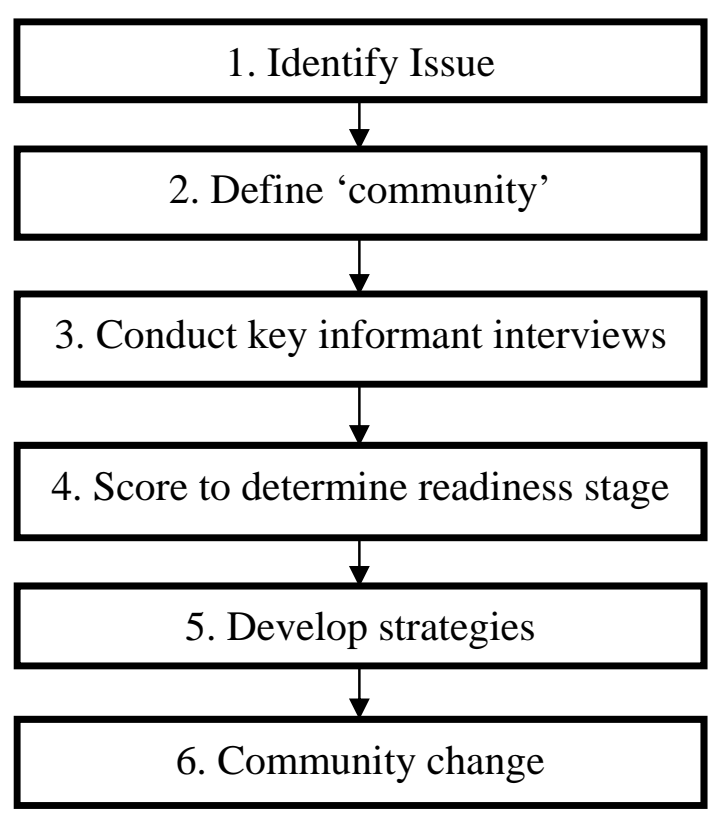

Figure 1 Process for using the Community Readiness Model Source: Adapted from Plested et al. 2006 
9.

Profession- 1. No awareness

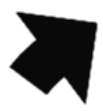

8. Confirmation/ Expansion

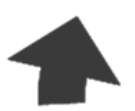

7. Stabilization

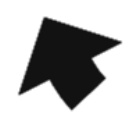

6. Initiation
Stages of Community

Readiness
2. Denial/ resistance

3. Vague awareness

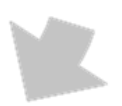
4
5. Preparation
4. Preplanning

Figure 2 The nine stages of Community Readiness 
Table 1. Six dimensions of readiness that influence a community's preparedness to take action on an issue

Dimension of readiness and interview topic ${ }^{1}$

Definition

A. Community efforts

To what extent are there efforts, programmes, and policies that address the issue?

B. Community knowledge of the efforts

To what extent do community members know about local efforts and their effectiveness, and are efforts accessible to all segments of the community?

C. Leadership

To what extent are appointed leaders and influential community members supportive of the issue?

D. Community climate

What is the prevailing attitude of the community toward the issue? Is it one of helplessness or one of responsibility and empowerment?

E. Community knowledge of the issues

To what extent do community members know about the causes of the problem, its consequences, and how it affects the community?

F. Resources related to the issue

To what extent are local resources - people, time, money, space, etc. - available to support efforts?

Source: Adapted from Plested et al. 2006

${ }^{1}$ Full interview topic guide can be obtained from the authors on request 
Table 2 Key informant participant characteristics

\begin{tabular}{|c|c|c|c|c|c|}
\hline Key Informant & Subcategory (number of schools) & Total & Subcategory (NS-SEC)* & Total & Overall Total \\
\hline Parents & $\begin{array}{l}\text { Least deprived school } \\
\text { Medium deprived school (2) } \\
\text { Most deprived school (4) }\end{array}$ & $\begin{array}{l}0 \\
2\end{array}$ & $\begin{array}{l}\text { Managerial and professional } \\
\text { occupations } \\
\text { Intermediate occupations } \\
\text { Small employers and own } \\
\text { account workers } \\
\text { Lower supervisory and technical } \\
\text { occupations } \\
\text { Semi-routine and routine } \\
\text { occupations } \\
\text { Unemployed }\end{array}$ & $\begin{array}{l}2 \\
3 \\
1 \\
0 \\
1 \\
3\end{array}$ & 10 \\
\hline Teachers and Teaching assistants ${ }^{\star \star}$ & $\begin{array}{l}\text { Least deprived school (1) } \\
\text { Medium deprived school (3) } \\
\text { Most deprived school (1) }\end{array}$ & $\begin{array}{l}1 \\
3 \\
2\end{array}$ & & & 6 \\
\hline Dinner staff & Most deprived school & 1 & & & 1 \\
\hline Government initiative leaders & $\begin{array}{l}\text { Healthy Schools Advisor (HSA) } \\
\text { School Food Advisor (SFA) }\end{array}$ & $\begin{array}{l}1 \\
1\end{array}$ & & & 2 \\
\hline Shop-keepers & $\begin{array}{l}\text { Urban area } \\
\text { Rural area }\end{array}$ & $\begin{array}{l}1 \\
1\end{array}$ & & & 2 \\
\hline Girl Guide leaders & & 6 & & & 6 \\
\hline Sports Coaches & $\begin{array}{l}\text { Sports Development Officers } \\
\text { (SDOs) } \\
\text { Football Development Officer } \\
\text { (FDOs) } \\
\text { Gymnastics Coach } \\
\text { Community Sports Coach } \\
\text { (CSC)/Play Ranger } \\
\text { School Sports Coach (SSP) }\end{array}$ & $\begin{array}{l}2 \\
1 \\
1 \\
1 \\
1\end{array}$ & & & 6 \\
\hline TOTAL N: & & & & & 33 \\
\hline
\end{tabular}


*National Statistics Socio-economic Classification derived from Self Coded method of self-reported occupation into one of five classes (Office for National Statistics, 2012). ${ }^{\star \star}$ Two of the teaching assistants were also dinner staff. 